\title{
Using Padlet to Enable Online Collaborative Mediation and Scaffolding in a Statistics Course
}

\author{
Henrik Skaug Sætra (D)
}

Citation: Sætra, H.S. Using Padlet to Enable Online Collaborative Mediation and Scaffolding in a Statistics Course. Educ. Sci. 2021, 11, 219. https://doi.org/10.3390/ educsci11050219

Academic Editor: Andrew Lumpe

Received: 16 April 2021

Accepted: 3 May 2021

Published: 5 May 2021

Publisher's Note: MDPI stays neutral with regard to jurisdictional claims in published maps and institutional affiliations.

Copyright: (C) 2021 by the author. Licensee MDPI, Basel, Switzerland. This article is an open access article distributed under the terms and conditions of the Creative Commons Attribution (CC BY) license (https:/ / creativecommons.org/licenses/by/ $4.0 /)$.
Faculty of Business, Languages and Social Sciences, Østfold University College, N-1757 Halden, Norway; henrik.satra@hiof.no

\begin{abstract}
Students often perceive statistics as a difficult subject, and it is frequently named as one of the primary causes of high dropout rates in economics educations in Norway. In order to support the learning process in statistics courses, and in order to make the courses more flexible, the author experimented with the use of Padlet in two different student groups taking an introductory course in statistics for economists. The purpose was to overcome the difficulty of engendering social engagement and activity and fostering effective mediation, scaffolding and collaborative learning in large student groups scheduled for traditional lectures in large auditoriums. The author's experiences and the students' evaluations of the model is presented here, along with the theoretical justification of the use of Padlet and the context in which it was tested. The results show that computer-supported collaborative learning can be an effective supplement or alternative to traditional study groups for those that either prefer this or cannot take part in regular study groups. The students used Padlet actively, and a majority of the students reported that it was a significant or highly significant factor in their learning process.
\end{abstract}

Keywords: statistics; Padlet; mediation; scaffolding; sociocultural learning; collaborative learning

\section{Introduction}

Statistics is a challenging subject both for students and professors, as it is often difficult for students to stay motivated throughout the challenging journey through a mixture of foundational mathematics and at times abstract and complex applications [1].

One particular challenge is associated with teaching introductory statistics courses for large groups of relatively fresh students in large auditoriums. In such settings it can be difficult to implement and foster collaborative learning, mediation and scaffolding-three important aspects of effective learning according to Lev Vygotsky. A key challenge is that large groups in auditoriums tend to engender relatively low levels of student engagement and activity, and this was historically the case both during and between lectures for the courses here described. These challenges are also relevant to remote learning more generally, and this makes the findings particularly interesting as COVID-19 has forced a large number of lecturers to implement remote teaching, creating a need to substitute natural social learning situations with virtual ones.

This article discusses one attempt to overcome this challenge by fostering computersupported collaborative learning (CSCL) through the active use of Padlet [2] in two different student groups taking an introductory statistics course for students of economics. The author's experiences and the students' feedback both demonstrate that CSCL was effective in fostering activity, and the students both considered it highly important for their learning processes and they appreciated and enjoyed it.

First, the background and context for the use of Padlet is presented, before the methods of gathering data is discussed. Then, the theoretical background for leveraging CSCL in this setting is presented, before the practical and pedagogical approach used to encourage students to use Padlet actively is discussed. Finally, the main findings are presented, 
which is primarily based on student feedback and the author's own experiences from these courses. In the conclusion, the key learning points for the successful use of Padlet or similar tools are summarized.

\section{Background and Context}

Statistics is an important skill in numerous educations, and the fundamentals of the course is the same for disciplines such as medicine, psychology, engineering, and economics. The experiences relayed in this article are from an introductory course in statistics for students of economics, but the experiences are likely to be at least partially transferable to other introductory courses in statistics as well. Economics students are dependent on mastering statistics in order to achieve proficiency in a number of other courses, and the course is consequently often taught early on in the education, along with mathematics.

Economics studies in Norway experience relatively high drop-out rates, as the students (a) face these technical and relatively difficult courses early on in their education, and (b) most institutions have large student groups where the teaching is often characterized by lecturing in large auditoriums and relatively little individual contact between the students and professors. Schewe [3] shows that 23.8 percent of the students that begin their bachelor's degree in economics and administration at one Norwegian institution drop out during the first semester, while an additional 30 percent drop out during the remainder of the first two years of the education. Numbers from Statistics Norway show that these degrees are popular and recruit a lot of students, but only 43 percent complete their degrees within the scheduled three years [4].

One possible explanation for the challenges experienced in these courses is that the students are taught statistics in relatively large groups in auditoriums. The two courses have traditionally emphasized traditional lectures with relatively little facilitation of betweenlecture activity by the institutions. This tends not to be particularly effective for fostering student engagement and high levels of student activity. High levels of engagement and student activity is often considered to be an important indicator of effective learning, also in relatively technical subjects such as statistics [5,6]. The opposite-low levels of activity-is an indicator of high risk of drop-out [7]. However, while studies find that high levels of activity is sometimes correlated with higher student performance, in some cases it is found that extremely high activity is correlated with low performance, as it can result from a lack of understanding of the subject matter [8]. In order to examine if Padlet and other digital tools (explained in more detail in Section 5) could increase engagement with the subject matter-with an emphasis on social mediation-and consequently lead to less drop-out and better student performance, the intervention described in this article was implemented. As discussed in more detail in Section 4, the primary goal was to increase students' social engagement with the subject matter, and less focus has been placed on individual student activity.

\section{Methods}

This article relays the experiences gained by testing CSCL in two introductory statistics classes for economics in two different Norwegian higher education institutions in the spring semester of 2019. Both courses are a part of a bachelor's degree in economics and administration, but in both cases some students from other disciplines (i.e., political science) took the course separately from the bachelor's degree. Both institutions are public institutions, whereas one (A) is a university college and the other (B) a university.

In institution $\mathrm{A}$, there were 137 registered students, and 103 of these handed in the first mandatory assignment. In institution B, there were 100 students enrolled, whereas 90 of them handed in the first mandatory assignment. The average age of the students was 24.8 years, and there was a slight overweight of male students (53 percent).

The methods used to gather data were in-depth interviews with student representatives (three, as the student group from institution B had two representatives) approximately 
midway in the semester, an simple introductory survey and a survey distributed to all students at the end of the semester. The interviews were scheduled for $1-1.5 \mathrm{~h}$, and were semi-structured. An interview guide consisting of the main topics to be covered was prepared, but the author allowed the representatives to bring up new topics whenever this seemed relevant. The introductory survey was conducted online (SurveyXact was used) during class, and the purpose of the survey was both to generate data that would be used in examples and exercised throughout the course, but the author also introduced a limited set of questions related to the student's access to study groups, how far away from the institution the lived, how they travelled to school, etc. The main closing survey was created in an online tool (SurveyXact) and was distributed to the students through the learning management system. The response rate for the survey was 70 and 50 percent. Some of the results from this survey is presented in Section 6 of the article. In addition to the author's own course-specific survey, both institutions evaluated the courses by survey at the end of the semester.

While the results of these evaluations and the students' performance were favorable, they have not been emphasized in this article, as the interventions were carried out in a situation in which too many variables (i.e., course material, lecturer, exam form) were changed compared to previous years for these effects to be attributed to the use of Padlet here examined. The experiences of the author and the students, as they help understand the effectiveness of Padlet in fostering mediation and scaffolding, is thus perceived as most important, and follow-up studies and similar interventions by researchers in which fewer changes are undertaken is needed to statistically show the effects of student performance following from the phenomena here described.

\section{Theoretical Background}

Lev Vygotsky is a key figure in educational and development psychology, and his work is highly influential in the pedagogical literature. This article mainly focuses on two of his key concepts: mediation and scaffolding. Vygotsky is often associated with the sociocultural theory of learning - a tradition that emphasizes the notion that people learn most effectively in social situations [9]. The learning context, and the community in which one learns, is considered to be of major importance. One reason is that we tend to reason and reach new insights in collaboration - through dialogue and interaction-in a process referred to as distributed intelligence [9]. There are numerous interpretations of what Vygotsky really proposed, and what sort of pedagogical approach most accurately represents his educational philosophy [10]. These debates are beyond the scope of the article, and the ideas of mediation and scaffolding as they are used here are relatively mainstream and accepted parts of his core philosophy.

Vygotsky believed that people do not merely absorb information, but process, engage with, and organize it [9]. A learning process may begin with the presentation of information, for example, in the form of a textbook or information presented during a lecture, but that in itself is not the end-or even main part-of the learning process.

Mediation is a term used to describe how information is processed and internalized through interactions with others, such as when an expert helps a novice make sense of a particular situation [9,11]. Since we never, according to Vygotsky, interact directly with the world the tools and signs we use to make sense of the world are mediational means of learning and understanding our physical and social contexts [12]. Textbooks and teachers can both be used to mediate information that we want the students to learn. However, as people's needs, existing knowledge, and experiences are highly diverse, individualized mediation is often required to facilitate effective learning. Computer mediation is a related, but slightly different phenomenon, and I here mainly focus on how computer-based tools are used to facilitate human mediation, and not on how the tools themselves mediate $[13,14]$.

Scaffolding is another term used for the process in which a learner is supported in the learning process, either by other human beings or various tools [15]. Learning is most effective when it occurs at the level beyond what the learner already knows very well, 
but not too far above the learner's current level. This learning "zone", which is naturally different for all individuals, is named the zone of proximal development (ZPD). In this zone, the learner struggles with performing autonomously, but they can perform with some assistance, and this particular form of assistance is named scaffolding. There are six key functions of scaffolding: recruitment, direction maintenance, frustration control, simplification, marking critical features, and demonstration [16].

\section{Fostering Collaborative Online Mediation and Scaffolding}

The main challenge addressed by the introduction of Padlet was the lack of student activity and active engagement with the subject matter both during and between the lectures. The author's goal as a lecturer was to be more accessible to students and to provide them with new and better means of accessing each other, without the need for allocating more resources to the course. This article focuses on the use of Padlet to foster collaborative learning, and this was one of several actions implemented during these courses. In addition to Padlet, the forum and test functionality in the learning management system (LMS) was used, and the author also created videos where various assignments were solved and discussed. It quickly became apparent that the students did not naturally or willingly use the forum in the LMS. Padlet, on the other hand was accepted much more readily.

From an initial survey distributed to the students, it was discovered that many students did not have a set group of fellow students with whom to form study groups, and most students did not live near or spend a lot of time on campus, thus limiting the potential of basing social learning on co-located study groups. A total of $64.4 \%$ of the students that did not have a study group answered that they would have wanted to be in one.

Working on the assumption that mediation, scaffolding and social learning are beneficial, the author decided to base voluntary between-lecture activity on the use of Padlet. This tool allows students to cooperate in various ways in real-time, and it allows for the posting of text, videos, photos, links, etc. It has been used for a broad range of applications, for example, for enabling student debates [17], to foster activity during lectures [18,19], creating learning modules (i.e., for the deaf [20]), as a message board or "graffiti wall" [21], in a variety of educations (i.e., collaborative language learning for language learning [22], improving writing skills $[23,24]$, or in music teaching [25], etc.).

It is also available as a mobile app, and thus allows for the quick posting of pictures of a student's notebook, for example, if a student is working on solving problems and has a need to show their progress and ask for input or help. Padlet also allows for push notifications to instantaneously notify the students who so desire of new activity on the class Padlet. The tool also allows for anonymous or registered use, and this was one of the main reasons for using this tool. While the article discusses the experiences of using Padlet, any service or application with similar functionality would serve to create the effects here discussed. Mural (mural.co) and Miro (miro.com) are other tools that are increasingly being used as digital collaborative whiteboards. One advantage with Padlet is that it can be used as a living, lasting, and ever-growing message board. This means that a very large number of posts can be kept track of, while simultaneously allowing students to immediately see the most recent activity first. The experiences and findings here discussed are in no way limited to Padlet itself, and Neumann [26] presents a range of alternatives that cover some or most of the functions in Padlet.

One challenge as a lecturer in large groups such as these is the number of e-mails and questions received through other arenas that address topics that might be of interest to at least one other student. The author thus introduced these courses by establishing and discussing one basic rule: All questions that might be of interest to at least one other student, and contain no sensitive or personal information, will not be answered by e-mail, but should be posted on Padlet.

This rule was met with both understanding and agreement, and while a lot of students adhered to the rule, it was also bolstered by implementing an additional mechanism: 
Whenever the author received questions on e-mail that were of interest to others, he anonymized the e-mail and posted it on Padlet with an answer (unless, as will be shown shortly, it was a question about statistics and not administrative matters). The student then merely received a reply to their e-mail stating that the question had been answered on Padlet, with a friendly reminder of the rule and the reason for doing it this way.

This was one of many ways to actively encourage and create what could be known as a tipping point of activity on Padlet, as early experience showed that the students would not regularly visit Padlet before things were actually happening there. Funneling all questions to the channel was the first step.

The second step was to use Padlet for creating tailored post-lecture activity around new problems and examples related to issues that it seemed that the students found challenging. During the lectures, questions and discussions were actively encouraged, and the author also used sli.do (http:/ / sli.do; accessed date 5 April 2021) to allow for anonymous questions during the lectures. The problem posted on Padlet turned out to be relatively popular, but the answers to the problems or examples were actively withheld until a number of students had proposed answers, approaches to the problems, and had discussed the proposed solutions to the others. These were all problems and examples made for the purpose of sharing on Padlet, so no answers were available in the textbooks or online. However, this approach requires the lecturer or an assistant to be a relatively active participant in the forum, as the students themselves have limited knowledge of the subjects, they may provide wrong answers or explanations, and they may be reluctant to perceive their fellow students as legitimate sources of expert knowledge [9]. In addition to this, it is important to prevent the development of group think, such as an overly positive evaluation of the group, the emergence of mind guards, stereotyping of non-members, and conformity pressure [27]. In order to get past the tipping point of activity, it is imperative that the students feel that it is safe and accepted to propose wrong answers.

In addition to this, the students were constantly encouraged to actively use Padlet for asking each other all questions that we did not have time to fully cover in class. They were also told to consider Padlet their extended study group. While students readily perceive all questions as legitimate in a study group - such as questions about mandatory assignments, etc.- - they initially considered asking and answering such questions on Padlet to be somewhat akin to cheating. This notion was actively discouraged and the student were encouraged to use Padlet for all questions they would have liked to ask their fellow students in any other study group setting. This was quickly accepted, and the main result of this was that the help those with study groups usually got from each other was now made available for a lot of students that otherwise would not have had it.

The purpose of using Padlet was to foster collaborative or cooperative learning [5] and to improve the conditions for the mediation and scaffolding of individual students both by the author and by the students in a collaborative learning environment. While statistics is a "hard" and technical subject, student activity is also highly important in these subjects $[5,6]$. As mentioned, it was desirable that those that did not have access to traditional student groups could also experience the benefits of collaborative learning and distributed cognition, and with the use of appropriate tools, these things can be achieved without physically gathering the students [9]. That the conditions of social learning can be created in digital arenas is also shown by, for example, studies on the use of digital communication forms in therapeutic settings [28,29].

\section{Results}

During the initial weeks of both courses, the author struggled to get the students to use Padlet or the LMS forums, and my dialogue with the class representatives suggested that it would most likely be difficult to achieve significant activity in any online forum. The representatives for both these student groups portrayed their groups as relatively passive in most classes, but they were active outside of lectures and performed well in most 
subjects. After consulting with the representatives, the author thus started emphasizing the possibility for and acceptance of using Padlet anonymously.

This, in combination with the author's active use of Padlet for posting extra problems and examples and questions from students, gradually led to an increase in the use of the platform. More and more students started using Padlet for a wide range of questions, and the questions ranged from advanced questions to very simple questions. This latter category of questions proved to be one of the most important aspects of using Padlet, as these were very basic questions that students rarely dare to ask in class, or directly to a lecturer or fellow students, in fear of looking stupid and being mocked. This was stressed both by the representatives and in the answers to the open question in the course evaluations. It became clear that quite a few students shared the need to ask these simple questions.

In addition, one highly beneficial consequence of these questions being asked was that fellow students quickly started jumping in to answer the questions and provide explanations to their fellow students. A relatively small group of "champions" emerged in both these groups, and these champions spontaneously took on the role of pseudo teaching assistants and guides to their fellow student, while they also used Padlet actively to ask more advanced questions themselves. A significant share of these champions relatively quickly started using Padlet as registered users, and discarded their anonymity. It was thus possible to know who many of these students were, and the author could see that these students clearly benefited from being the "more capable peers" [30] for their fellow students, while they themselves also received guidance from more advanced students and the author.

A major finding is that a large number of students frequented and paid attention to Padlet without actively posting. At the end of the semester, 78 percent of the students reported having used Padlet, and of these, their frequency of use is distributed as shown on the top in Figure 1. The students were also asked how important they perceived Padlet to have been for their learning, as shown in the bottom of the figure.

A total of 31.65 percent of the students believed that Padlet was highly significant for their learning, while an additional 48.1 percent perceived it to be significant. A total of 44.3 percent of the Padlet users used Padlet more than 10 times during the semester, and a lot of students used it between 3 and 9 times. This reflects the author's experience that there was a set group of students that were highly active throughout the semester, while a lot of other students used Padlet very actively in three key periods: around the first and second mandatory assignment and in preparation for the exams.

It is worth noting that a higher percentage of the female Padlet users answered that they used it frequently (see Figure 2) and the female students seemed to consider Padlet to be more significant for their learning than did male students (see Figure 3). The correlation between gender and frequency was 0.26 , and significant at the 0.05 level. The correlation between gender and importance was not statistically significant. The correlation between frequency and importance is 0.320 and significant at the 0.01 level, indicating that high frequency of use is associated with a high evaluation of the significance for a student's learning.

The answers to the open questions on the end of the semester survey also clearly show that a large number of students appreciated the use of Padlet, and no students voiced any negative opinions about the use of this tool. A number of students stated that it had been of great help, and clearly stated that it should be used more, and in other classes as well. 


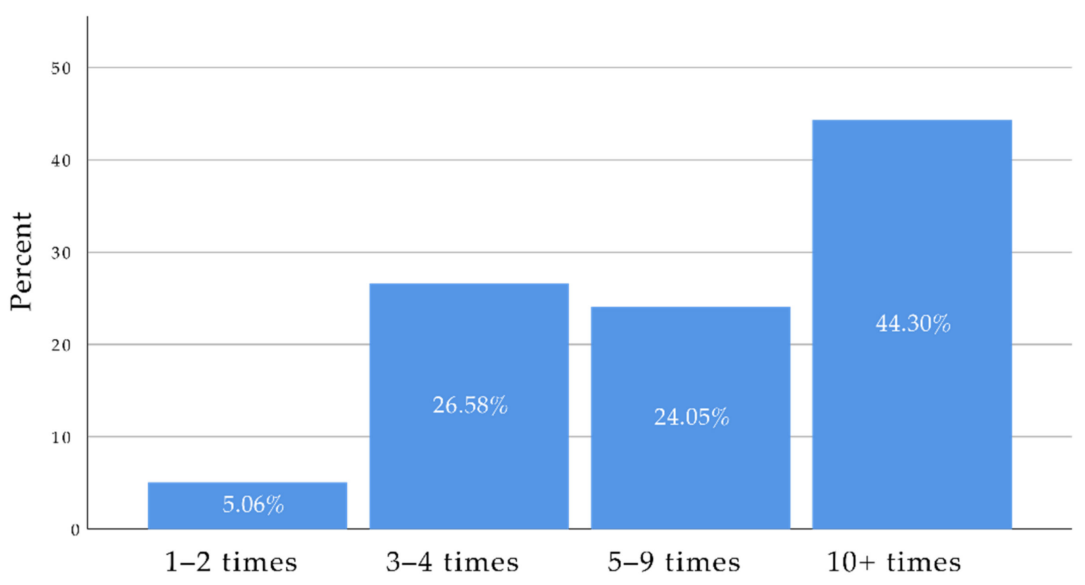

How many times did you visit Padlet?

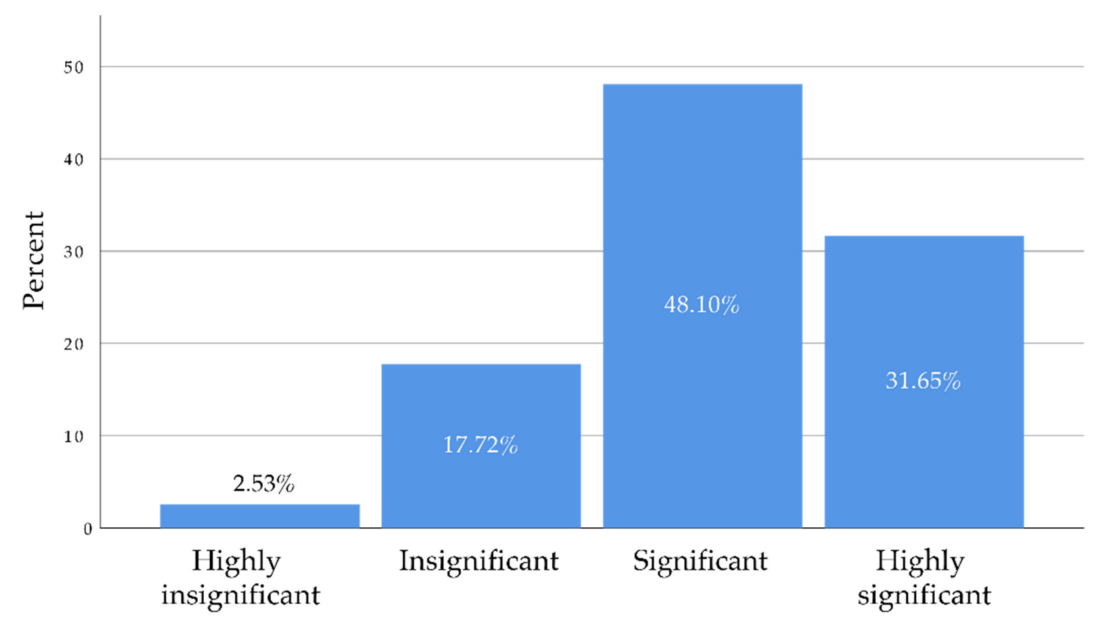

How important was Padlet for your learning in this course?

Figure 1. Top: frequency of Padlet use for those that used the platform. Bottom: perception of the importance of Padlet for learning.

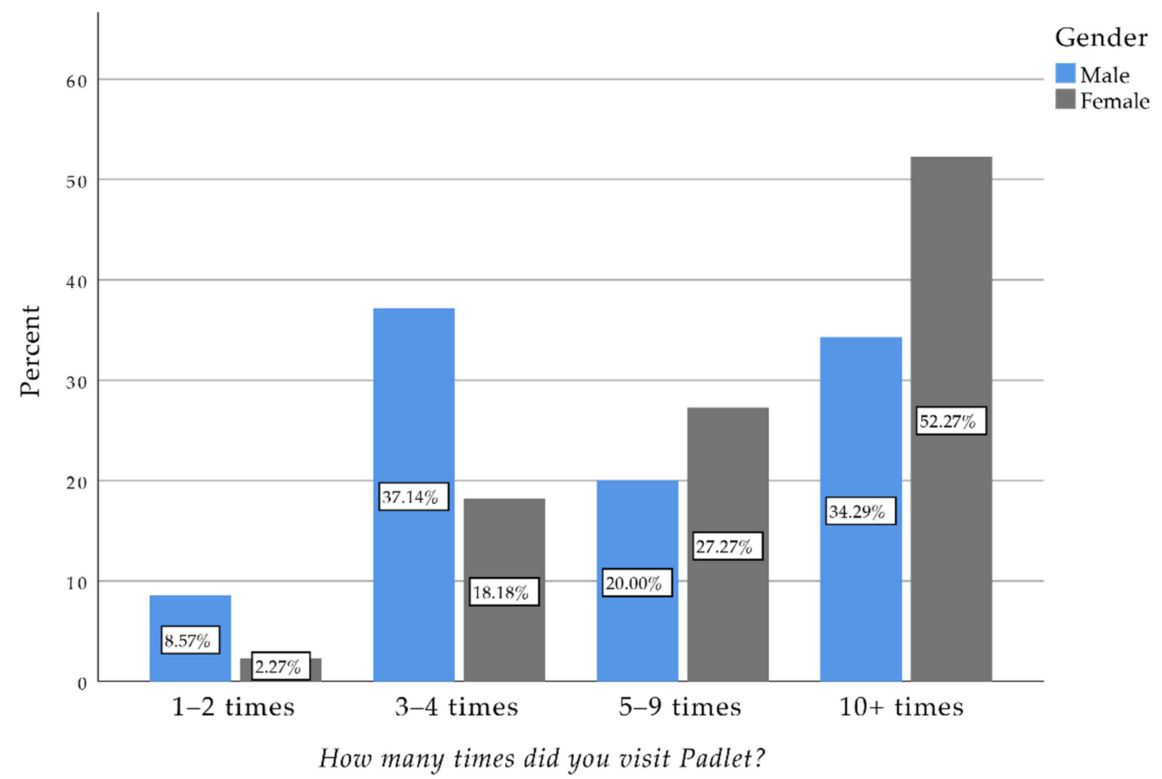

Figure 2. Frequency of use by gender. 


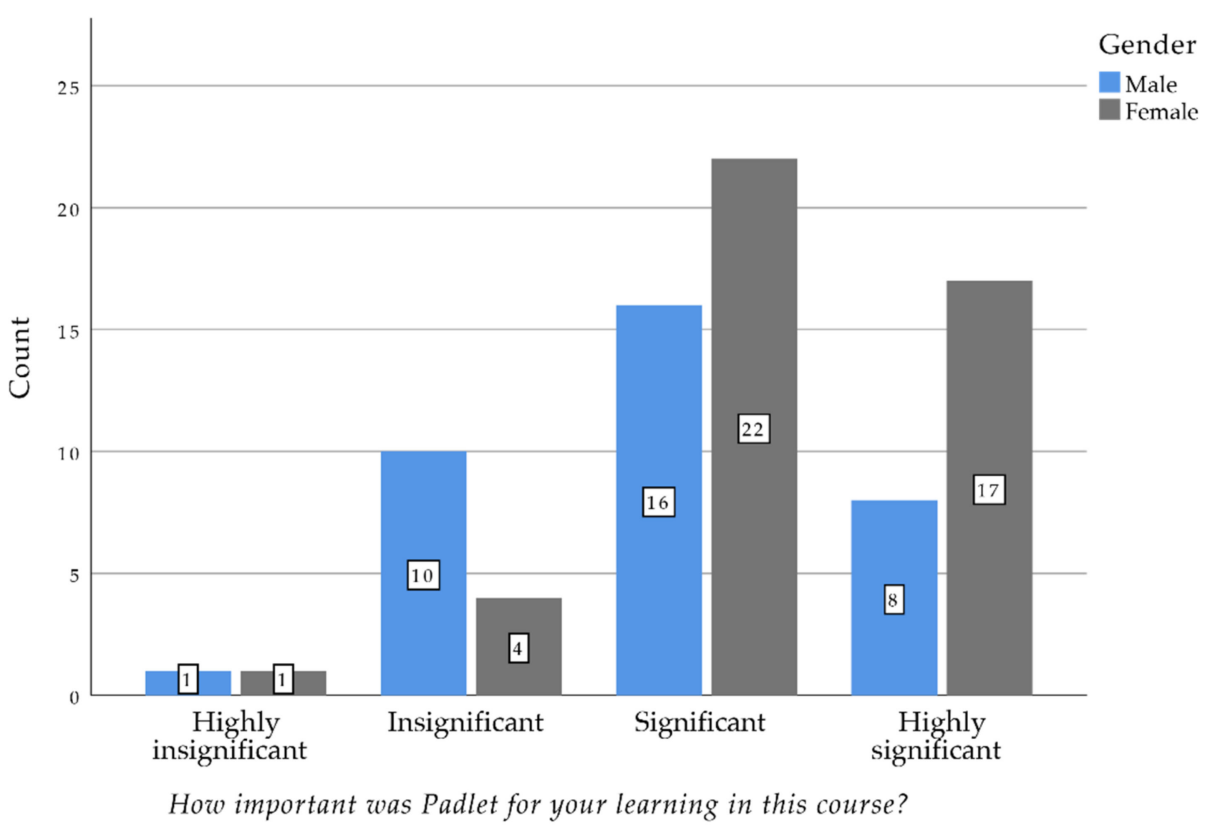

Figure 3. Evaluation of Padlet by gender.

The institutions' evaluations of the courses showed that the students were very satisfied with the courses, and many students requested that other lecturers should use the same approach in other courses. The exam results for both courses were improved from previous years, but as both courses had a new lecturer, new exams, and the courses were partially administratively changed in various ways, these results are of limited value and thus not presented here. The phenomena described in this article highlight the potential effectiveness for using tools such as Padlet to foster mediation and scaffolding, and while the results in the two courses here described are highly positive, further research on the exact effects on student performance and drop-out is required.

\section{Conclusions}

Padlet proved to be an effective tool for CSCL, and the author's experience from two different student groups taking an introductory statistics course showed that the students used it, enjoyed it, and found it to be highly valuable for their learning process. The author was able to mediate and scaffold individual students more effectively than he would otherwise have been able to, and a social learning environment-or fellowshipalso formed on Padlet, in which students engaged in collaborative learning and the active scaffolding of fellow students.

With these positive results, a number of key lessons and recommendations were suggested by these experiments with Padlet for CSCL:

- Anonymity was highly important, as it (a) enabled students that would otherwise not ask questions to participate, and (b) resulted in the asking of "stupid" questions that would most likely not have been asked in the absence of the possibility to ask them anonymously.

- Reaching a tipping point of activity requires active encouragement and effort by the lecturer or aides. However, once it is reached, the platform takes on a life of its own as the activity is seen as its own justification for actively checking in.

- A lot of students use the mobile app, and students enabling notifications seem to foster a more active and responsive community.

- A lot of students will mainly use the arena as they prepare for assignments or the exams, but this is not a problem if a small and continuously active community is formed. 
- Encourage "champions" to emerge, as these are highly effective in helping and guiding fellow students, and they seem to thrive in the role as champion, both personally and academically. They receive respect and gratitude from their fellow students, and they provide significant help, assistance, and activity on the platform.

- Enforce relatively strict rules for channels of communication in order to foster activity on the platform, and be wary of providing answers and responses to academic questions too quickly, as this will tend to "crowd out" student activity, pacify the student group who quickly grow to expect answers from you, and it will prevent the emergence of champions.

Funding: This research received no external funding.

Institutional Review Board Statement: Not applicable.

Informed Consent Statement: Not applicable. The students were informed of the purpose of the studies and the potential anonymized use in research.

Data Availability Statement: Not applicable.

Conflicts of Interest: The author declares no conflict of interest.

\section{References}

1. Gelman, A.; Nolan, D. Teaching Statistics: A Bag of Tricks; Oxford University Press: Oxford, UK, 2017.

2. Padlet. Padlet. Available online: http:/ / www.padlet.com (accessed on 18 January 2021).

3. Schewe, T. Frafall og gjennomstrømming for studenter i økonomiske fag ved Høgskolen i Østfold—En mikroanalyse for studentkull H2014. In Proceedings of the FIBE Conference, Bergen, Norway, 4-5 January 2018.

4. SSB. Gjennomføring ved Universiteter og Høgskoler. Available online: https:/ / www.ssb.no/hugjen (accessed on 1 June 2020).

5. Garfield, J. Teaching statistics using small-group cooperative learning. J. Stat. Educ. 1993, 1. [CrossRef]

6. Freeman, S.; Eddy, S.L.; McDonough, M.; Smith, M.K.; Okoroafor, N.; Jordt, H.; Wenderoth, M.P. Active learning increases student performance in science, engineering, and mathematics. Proc. Natl. Acad. Sci. USA 2014, 111, 8410-8415. [CrossRef] [PubMed]

7. Cohen, A. Analysis of student activity in web-supported courses as a tool for predicting dropout. Educ. Technol. Res. Dev. 2017, 65, 1285-1304. [CrossRef]

8. Casey, K.; Azcona, D. Utilizing student activity patterns to predict performance. Int. J. Educ. Technol. High. Educ. 2017, 14, 1-15. [CrossRef]

9. Ormrod, J.E. Human Learning; Pearson Higher Ed.: London, UK, 2016.

10. Del Río, P.; Álvarez, A. Inside and Outside the Zone of Proximal Development. An ecofunctional Reading of Vygotsy. In The Cambridge Companion to Vygotsky; Daniels, H., Michael, C., Wertsch, J.V., Eds.; Cambridge University Press: Cambridge, UK, 2007.

11. Feuerstein, R.; Feuerstein, R.; Falik, L.H. Beyond Smarter: Mediated Learning and the Brain's Capacity for Change; Teachers College Press: New York, NY, USA, 2015.

12. Wertsch, J.V. Mediation. In The Cambridge Companion to Vygotsky; Daniels, H., Michael, C., Wertsch, J.V., Eds.; Cambridge University Press: Cambridge, UK, 2007; pp. 178-192.

13. Kaptelinin, V. Computer-mediated activity: Functional organs in social and developmental contexts. In Context and Consciousness: Activity Theory and Human-Computer Interaction; Nardi, B.A., Ed.; MIT Press: Cambridge, UK, 1996; pp. 45-68.

14. Wertsch, J.V. Computer mediation, PBL, and dialogicality. Distance Educ. 2002, 23, 105-108. [CrossRef]

15. Lesgold, A.M. Learning for the Age of Artificial Intelligence: Eight Education Competences; Routledge: London, UK, 2019.

16. Wood, D.; Bruner, J.S.; Ross, G. The role of tutoring in problem solving. J. Child Psychol. Psychiatry 1976, 17, 89-100. [CrossRef] [PubMed]

17. Dewitt, D.; Alias, N.; Siraj, S. Collaborative learning: Interactive debates using Padlet in a higher education institution. In Proceedings of the International Educational Technology Conference (IETC 2015), Istanbul, Turkey, 27-29 May 2015.

18. Ellis, D. Using Padlet to increase student engagement in lectures. In Proceedings of the ECEL2015-14th European Conference on e-Learning: ECEl2015, Hatfield, UK, 29-30 October 2015; p. 195.

19. Fuchs, B. The writing is on the wall: Using Padlet for whole-class engagement. LOEX Q. 2014, 40, 7.

20. DeWitt, D.; Alias, N.; Ibrahim, Z.; Shing, N.K.; Rashid, S.M.M. Design of a learning module for the deaf in a higher education institution using padlet. Procedia-Soc. Behav. Sci. 2015, 176, 220-226. [CrossRef]

21. Wood, M. Padlet: A Graffiti Wall for Today's Agriculture Teacher. Agric. Educ. Mag. 2016, 88, 20.

22. Rashid, A.A.; Yunus, M.M.; Wahi, W. Using Padlet for collaborative writing among ESL learners. Creat. Educ. 2019, 10, 610-620. [CrossRef]

23. Lestari, S. Implementing padlet application to improve writing ability in English writing skill for non English department students. LET Linguist. Lit. Engl. Teach. J. 2017, 7, 1-16. 
24. Lestari, P.Y.; Kurniawan, E.H. Padlet as Media to Improve Writing Mastery of English Department Students of Uniska $2015-2016$. Engl. FRANCA Acad. J. Engl. Lang. Educ. STAIN Curup 2018, 2, 12.

25. Dunbar, L. Using padlet to increase student interaction with music concepts. Gen. Music Today 2017, 30, 26-29. [CrossRef]

26. Neumann, T. Alternatives for Digital Walls like Padlet. In Digital Education Team Blog; UCL: London, UK, 2020.

27. Janis, I.L. Groupthink: Psychological Studies of Policy Decisions and Fiascoes; Houghton Mifflin: Boston, MA, USA, 1982.

28. Sucala, M.; Schnur, J.B.; Constantino, M.J.; Miller, S.J.; Brackman, E.H.; Montgomery, G.H. The therapeutic relationship in e-therapy for mental health: A systematic review. J. Med. Internet Res. 2012, 14, e110. [CrossRef] [PubMed]

29. Cook, J.E.; Doyle, C. Working alliance in online therapy as compared to face-to-face therapy: Preliminary results. Cyber Psychol. Behav. 2002, 5, 95-105. [CrossRef] [PubMed]

30. Vygotsky, L.S. Mind in Society: The Development of Higher Psychological Processes; Harvard University Press: Cambridge, MA, USA, 1980. 